\title{
Inverse strain rate sensitivity of bendability of an AZ31 sheet in three-point bending
}

\author{
B. Li, S.J. Horstemeyer, A.L. Oppedal, P.T. Wang, M.F. Horstemeyer \\ Center for Advanced Vehicular Systems, Mississippi State University, 200 Research Blvd., Starkville, MS 39759
}

Keywords: Strain rate sensitivity; magnesium; bending; deformation

\begin{abstract}
Three-point bending tests were performed on as-rolled and annealed (at $150{ }^{\circ} \mathrm{C}$ ) AZ31 sheet specimens at various displacement rates $(1.0,5.0$ and $50.0 \mathrm{~mm} / \mathrm{min})$ at room temperature. The as-rolled specimens present a negative sensitivity, i.e., the bending angle decreases as the strain rate increases; however, the annealed specimens show a positive sensitivity, i.e., the bending angle increases as the strain rate increases. Such an inverse strain rate sensitivity of sheet bending may significantly impact the sheet forming of Mg alloys.
\end{abstract}

\section{Introduction}

Magnesium $(\mathrm{Mg})$ alloys are of interest as potential replacement materials for heavier aluminum and steel alloys in transportation industries due to their low densities $(1740 \mathrm{~kg} / \mathrm{m} 3$ for pure $\mathrm{Mg}$ ) and high strength-to-weight ratios. The inherently low ductility and fracture toughness of wrought $\mathrm{Mg}$ alloys at room temperature (RT), consequences of their hexagonal-close packed (HCP) crystal structures, have largely limited applications to cast materials. The number of easy slip systems is insufficient to satisfy the von Mises criterion [1]. This requires five independent slip systems to accommodate the compatibility strain at grain boundaries, despite the multiplicity of slip systems on basal, prismatic, and pyramidal planes, with the basal slip being the easiest. Irrespective of c/a ratio, HCP metals twin profusely during plastic deformation. The main twinning systems in HCP metals are either on the first order or the second order pyramidal planes [2,3], allowing twinning to accommodate the strain in the direction perpendicular to the basal plane. Alternatively, type $\langle a\rangle$ dislocations (on basal and prismatic planes) are unable to do the same. Hence, twinning plays an important role in plastic deformation of HCP metals. Twin-slip interactions give rise to unique mechanical behavior in $\mathrm{Mg}$ alloys that vastly differs from other alloys with high symmetry crystal structures in which dislocation slip dominates deformation [4-6].

Due to the relatively poor ductility of wrought $\mathrm{Mg}$ alloys at room temperature, conventional forming processes (e.g., stamping) require elevated temperatures at which dislocation slip and dynamic recrystallization are dominant [7-13]. Concerns about hot forming of $\mathrm{Mg}$ alloys ( $\sim 450{ }^{\circ} \mathrm{C}$ ) stem from high energy consumption and manufacturing costs. One approach to better understanding RT deformation mechanisms in $\mathrm{Mg}$ is through the study of tests involving simple strain paths. Among these is bending, which occurs in numerous sheet forming processes [14$15]$.

We recently uncovered highly localized twin bands that developed during quasi-static, three-point bending of a wrought Mg AZ31 alloy at RT using in-situ electron backscatter diffraction (EBSD) [16]. Inside the twin bands, a high density of deformation twins was present; however, outside of the twin bands, twins were completely absent. Although the microstructure and mechanical properties of wrought $\mathrm{Mg}$ AZ31 have been extensively studied [17-25] over the past few decades, understanding of what occurs in the microstructure during bending and how the microstructure evolves require further investigation. Previous efforts have, in fact, focused on mechanical properties of AZ31 Mg alloys in uniaxial tension or compression [18-25] at various temperatures and strain rates. But no effort has been made to directly study strain rate dependence in sheet bending in which the stress state is different from that in uniaxial deformations. The purpose of this study is to investigate strain rate dependence $\left(3.0 \times 10^{-4} \mathrm{~s}^{-1}-\right.$ $1.5 \times 10^{-2} \mathrm{~s}^{-1}$ ) of an AZ31 Mg alloy during three-point bending at room temperature.

\section{Experimental Methods}

The starting material was a hot rolled $\mathrm{Mg}$ AZ31 tooling plate with a composition of $\mathrm{Mg}-3 \% \mathrm{Al}-1 \% \mathrm{Zn}$ (wt. \%) and $6.0 \mathrm{~mm}$ thickness. The plate was heated to $400{ }^{\circ} \mathrm{C}$ by an infrared heating source and rolled at an average of $23 \%$ reduction per pass with a total of six passes to reach the final $1.0 \mathrm{~mm}$ [26]. Specimens with a dimension $60 \times 10 \times 1 \mathrm{~mm}^{3}$ were cut from the rolled sheet for threepoint bending tests. Some of the specimens were annealed at 150 ${ }^{\circ} \mathrm{C}$ for an hour in a vacuum furnace filled with Argon gas, and then cooled to ambient temperature inside the furnace to prevent oxidation. Annealing at other temperatures $\left(100,200\right.$, and $\left.300{ }^{\circ} \mathrm{C}\right)$ was also conducted, but the results will be presented elsewhere. The purpose of annealing is to study how initial microstructure affects the bending behavior.

The three-point bending tests were conducted on an Instron 5882 . A fixture for three-point bending was designed and machined with a span of $25 \mathrm{~mm}$ between the two supporting points. The bending tests were performed with displacement control. Three displacement rates were used in our tests: $1.0 \mathrm{~mm} / \mathrm{min}, 5.0$ $\mathrm{mm} / \mathrm{min}$, and $50.0 \mathrm{~mm} / \mathrm{min}$, corresponding to maximum strain rates about $3.0 \times 10^{-4} \mathrm{~s}^{-1}, 1.5 \times 10^{-3} \mathrm{~s}^{-1}$ and $1.5 \times 10^{-2} \mathrm{~s}^{-1}$, respectively. In this study, all bends were parallel to the transverse direction (TD). Our results reveal a surprising phenomenon in annealed specimens.

The microstructures of the as-rolled and the annealed specimens were examined by optical microscopy. Metallographic observations were made on the through-thickness cross section following standard procedures. The polished specimens were etched for 3 seconds with a solution of $70 \mathrm{ml}$ ethanol, $10 \mathrm{ml}$ distilled water, $10 \mathrm{ml}$ acetic acid, and $4 \mathrm{~g}$ picric acid.

The textures of the as-rolled and the annealed AZ31 sheets were examined by X-ray diffraction (XRD) using a Regaku SmartLab $\mathrm{X}$-ray diffractometer with a $\mathrm{Cu}-\mathrm{K} \alpha$ radiation source, $40 \mathrm{kV}$ operating voltage, and a $30 \mathrm{~mA}$ current. Six pole figures, i.e., $\{10 \overline{10}\},\{10 \overline{1} 1\},\{0002\},\{10 \overline{1} 2\},\{11 \overline{2} 0\}$ and $\{10 \overline{1} 3\}$ were measured. 
The orientation distribution functions (ODFs) were calculated using the measured pole figures after corrections for background and defocusing effects. The recalculated pole figures based on the ODFs were plotted by MTEX [27]. The texture was measured such that the XRD data were collected from the same specimen. First, a piece of the as-rolled material was cut and the surface was slightly polished. Then XRD was performed on the polished surface. After the XRD measurement, the same specimen was annealed at $150^{\circ} \mathrm{C}$, and then the texture of the annealed specimen was measured on the same polished surface.
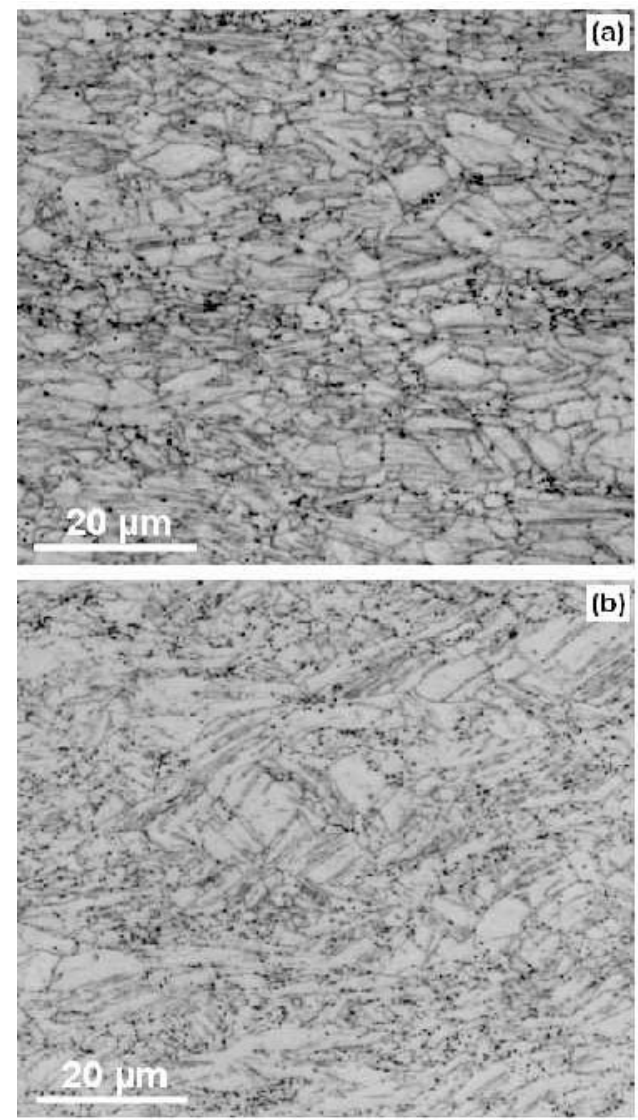

Figure 1. Optical metallography of the microstructures of the AZ31 Mg alloy sheet. (a) As-rolled Mg AZ31 alloy sheet. High density twins can be observed. (b) Annealed $\mathrm{Mg}$ AZ31 alloy sheet at $150^{\circ} \mathrm{C}$ for an hour. No significant change in grain size occurred after annealing.

\section{Results and Discussions}

Figure 1 shows the microstructures of both the as-rolled and the annealed Mg AZ31 sheet specimens. The microstructures were examined on the through-thickness cross-sections. In Figure 1a, the initial microstructure is comprised of a high density of $\{10 \overline{1} 2\}<10 \overline{11}>$ twins, which were generated during hot rolling at a relatively high strain rate and large strains [23]. After annealing at $150{ }^{\circ} \mathrm{C}$ for an hour, no measurable change in grain size occurred (Figure 1b).
The texture of the as-rolled and the annealed specimens is shown in Figure 2. Both pole figures are typical of rolled $\mathrm{Mg}$ alloys with a strong basal pole (the basal plane is approximately parallel to the rolling direction). An extra intensity spot appears in the $\{10 \overline{10}\}$ pole figure after annealing. The maximum intensity remains almost identical. No significant changes in the texture occurred after annealing, although the defect structure may have changed in terms of dislocation density and configurations due to recovery
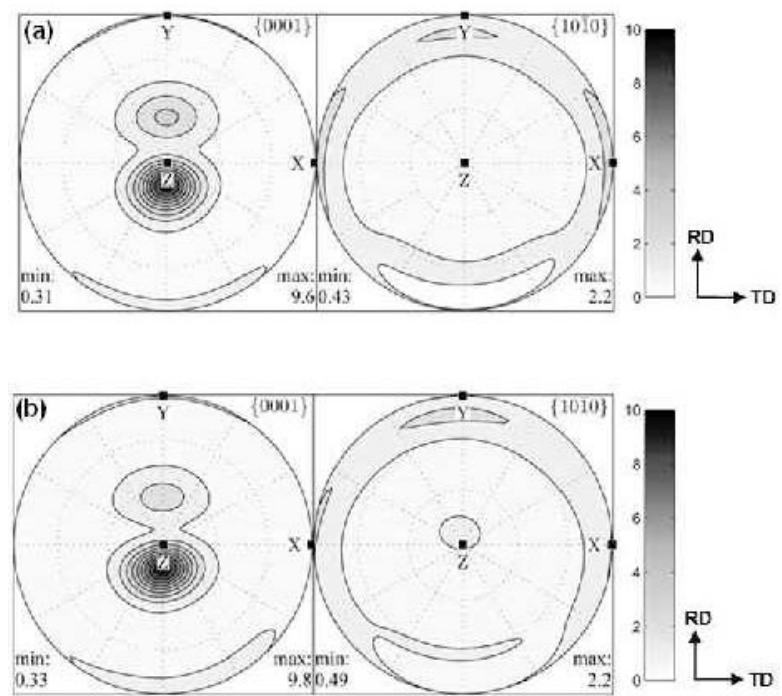

Figure 2. X-ray diffraction analysis of the texture in the Mg AZ31 sheet materials. (a) Pole figure of the as-rolled Mg AZ31. A strong basal texture can be observed, typical of rolled sheets of $\mathrm{Mg}$ alloys. A split in the rod texture is present. (b) Pole figure of the $\mathrm{Mg} A Z 31$ annealed at $150^{\circ} \mathrm{C}$ for an hour before bending tests. No significant changes in the texture are evident.

The load-displacement profiles from the three-point bending tests are shown in Figure 3 (the loads are negative because the bending was performed in compression mode of the machine). For the asrolled materials, all specimens failed (fractured) at all displacement rates, i.e., 1.0, 5.0 , and $50.00 \mathrm{~mm} / \mathrm{min}$. As expected, cracks initiated in the tension zone of each specimen. In general, for the as-rolled $\mathrm{Mg} \mathrm{AZ31}$ sheet material, the displacement to failure (the plummet in the load-displacement profiles) decreases as the displacement rate increases, as seen in the Figure $3 \mathrm{a}$. In sharp contrast, the load-displacement behavior of the annealed specimens revealed much different behavior. At displacement rates of 1.0 and $5.0 \mathrm{~mm} / \mathrm{min}$, the annealed specimens failed, even though at $5.0 \mathrm{~mm} / \mathrm{min}$, the displacement to failure was somewhat larger than that at $1.0 \mathrm{~mm} / \mathrm{min}$, corresponding to a larger bending angle. Surprisingly, the annealed specimen did not fail as the displacement increased to $50.0 \mathrm{~mm} / \mathrm{min}$, and three-point bending continued until reaching the limit of the bending fixture, creating an unexpectedly large bending angle (Figure $3 b$ ). In this scenario, the gradual decrease in the load as the displacement increases is due to the sliding of the sheet specimen over the two supporting 
points as the bending angle increased to a certain value. Sliding also caused the serrations in the load-displacement curves.

To better reveal this interesting bending behavior, we recorded the three-point bending process, and selected snapshots are shown in Figure 4. At 1.0 and $5.0 \mathrm{~mm} / \mathrm{min}$ displacement rates, both specimens failed (see $4 \mathrm{~d}$ and $4 \mathrm{e}$ ) although the bending angle at 5.0 $\mathrm{mm} / \mathrm{min}$ was slightly larger than that at $1.0 \mathrm{~mm} / \mathrm{min}$. At 5.0 $\mathrm{mm} / \mathrm{min}$, the specimen did not fail and a large bending angle was
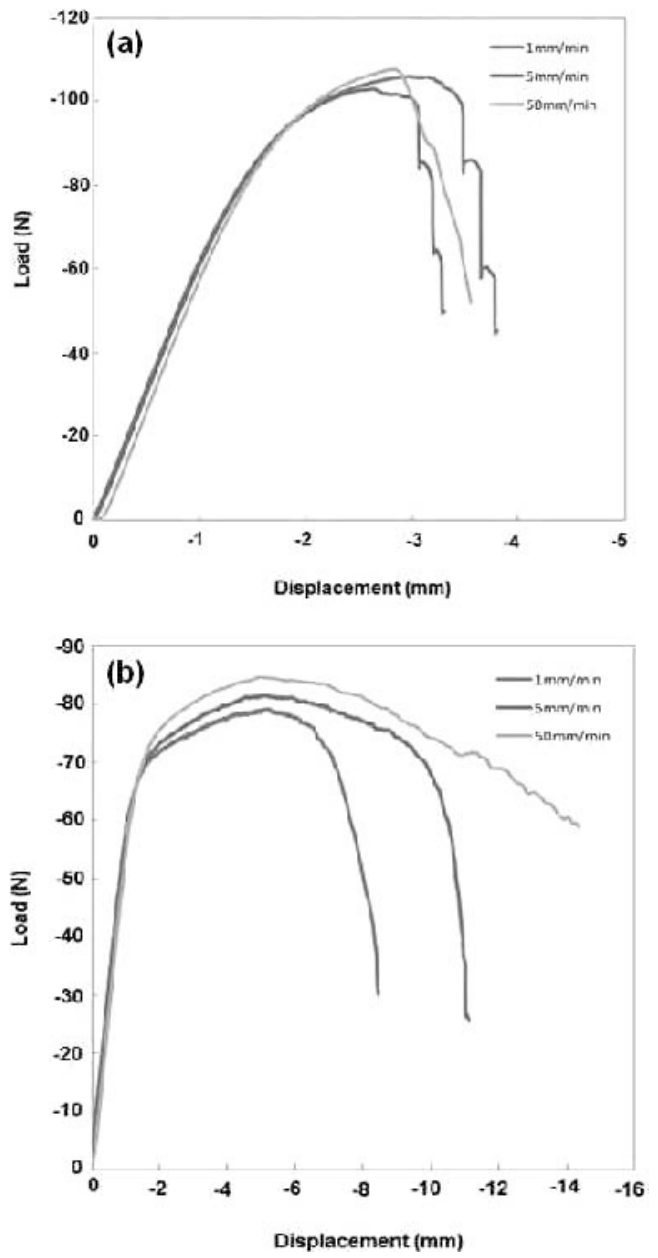

Figure 3. Load-displacement curves from the room temperature bending tests. All the bends are parallel to the transverse direction (TD). (a) As-rolled specimens. All the specimens failed at all strain rates, but the slower strain rates generate larger bending angles. (b) Specimens annealed at $150{ }^{\circ} \mathrm{C}$ for an hour. At lower strain rates, 1.0 $\mathrm{mm} / \mathrm{min}$ and $5.0 \mathrm{~mm} / \mathrm{min}$, both specimens failed, but the $5.0 \mathrm{~mm} / \mathrm{min}$ specimen failed with a larger displacement. At $50.00 \mathrm{~mm} / \mathrm{min}$, no specimen failed. An inverse strain rate sensitivity can be observed.

achieved (Figure 4c). Visual examination revealed that cracks were initiated in the tension zone at displacement rates 1.0 and 5.0 $\mathrm{mm} / \mathrm{min}$ (Figure $4 \mathrm{~d}, 4 \mathrm{e}$ ); however, no cracks were observed in the tension zone of specimens deformed at $50.0 \mathrm{~mm} / \mathrm{min}$ (Figure $4 \mathrm{f}$ ).
We repeated our bending tests with another set of specimens which were cut in the same direction and annealed under the same condition, and we found the observed behavior is repeatable.

Bends parallel to the rolling direction (RD) were also carried out, and no specimen failed at all strain rates. Whether similar inverse strain rate sensitivity exists in this direction requires further investigations.

Compared with the as-rolled specimens (Figure 3a), the annealed specimens show improved bending angle because of the change in the defect structures due to the heat treatments. The dislocation density decreases in the parent grains due to recovery, contributing to the decrease in strength (Figure 3). At the same displacement rate, the displacement to failure of an annealed specimen is larger than that of the as-rolled specimen. However, the bending behavior of the annealed specimens displays what we refer to as inverse strain rate sensitivity in bending: as the displacement rate increases, the bending angle increases. We have not found any indication of this phenomenon being previously reported in the literature on $\mathrm{Mg}$ alloys. This inverse strain rate sensitivity of the annealed sheet during bending observed in our experiments is counter-intuitive. One potential explanation is that the ductility of the annealed specimens is improved as the strain rate increases. But, available data in previous reports show that, in uniaxial tension, the ductility of $\mathrm{Mg}$ alloys presents a negative strain rate sensitivity [16-18]. The strain to failure in uniaxial compression behaves in a similar manner. Recently, Khan et al. [16] conducted extensive testing on a Mg AZ31 alloy in uniaxial tension, compression, and shear loading over a range of temperatures and strain rates. They showed that the material presents positive strain rate sensitivity in terms of flow stress at all strain rates at room and elevated temperatures. At a given temperature, their data suggests that the ductility decreases as strain rate increases. Maksoud et al. [17] studied deformation of a $\mathrm{Mg}$ AZ31 alloy under tension at different strain rates and temperatures. They showed that the ductility of the material increases as the strain rate decreases. Yin et al. [18] observed similar behavior in uniaxial tensile tests at different temperatures and strain rates in a hot-rolled $\mathrm{Mg}$ AZ31 Mg alloy. Hence, it would be inappropriate to conclude that the inverse strain rate sensitivity of the bending behavior of the annealed $\mathrm{Mg}$ AZ31 sheet is due to improved ductility.

It is worth noting that the stress state in three-point bending is quite different from uniaxial tension or compression. In threepoint bending, a gradient of strain through the specimen thickness is created and the strain reverses signs at the neutral axis. Hence, it can be anticipated that the deformation modes, i.e., slip and twinning in the tension and the compression zones of the as-rolled and the annealed specimens are significantly different. In the asrolled specimens, the microstructure is nearly saturated with deformation twins, as shown in Figure 1a. Although the stress state in the compression zone favors the $\{10 \overline{1} 2\}<10 \overline{11}>$ twinning in bending [25], deformation by twinning should be insignificant. Slip by pyramidal dislocations is activated because the grains are oriented favorably for pyramidal slip (the shear factors for basal and prismatic slip are close to zero). In the tension zone, detwinning of the pre-existing twins first occurs, and dislocation slip dominates plastic deformation. Hence, we would expect a negative strain rate sensitivity of bending because hardening by dislocation interactions in the tension zone has a positive strain rate sensitivity [16]. 

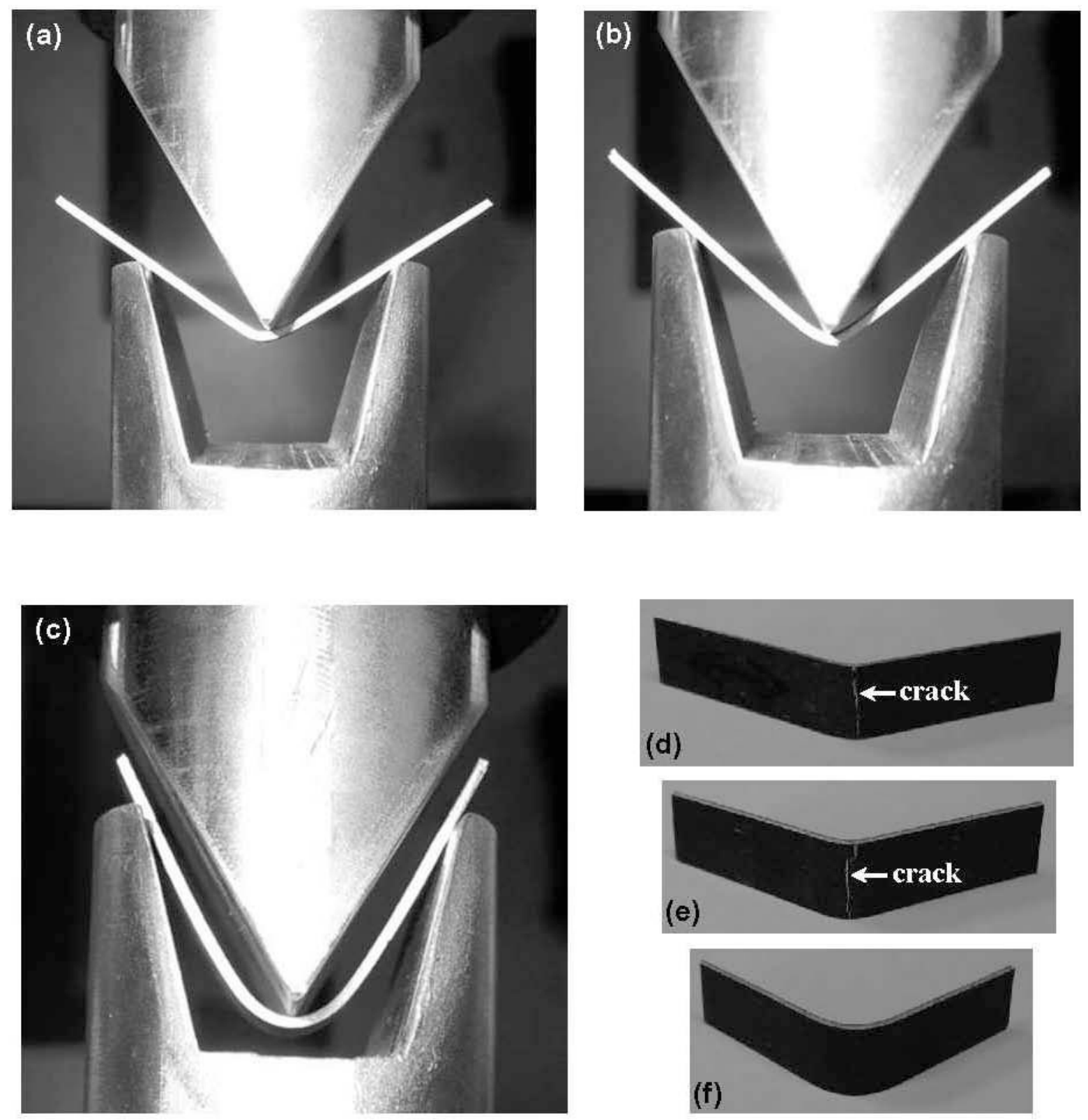

Figure 4. Room temperature bending tests at various displacement rates of the $\mathrm{Mg} \mathrm{AZ} 31$ sheets annealed at $150{ }^{\circ} \mathrm{C}$ for an hour. (a) $1.0 \mathrm{~mm} / \mathrm{min}$, the specimen failed with cracks initiated in the tension zone; (b) $5.0 \mathrm{~mm} / \mathrm{min}$, the specimen failed but with a larger bending angle than that in the $1.0 \mathrm{~mm} / \mathrm{min}$ test; (c) $50.0 \mathrm{~mm} / \mathrm{min}$, the specimen did not fail and was bent to a large angle; (d-f) Visual examinations: (d) $1.0 \mathrm{~mm} / \mathrm{min}$, cracks can be seen in the tension zone; (e) $5.0 \mathrm{~mm} / \mathrm{min}$, cracks can be seen in the tension zone; (f) $50.0 \mathrm{~mm} / \mathrm{min}$, no cracks were initiated. 
In the case of the annealed specimens, recovery occurs and hence the deformation mechanisms differ from the as-rolled specimens. Dislocation density and configurations changed as a result of annealing. How these microstructural changes affect the activation of the deformation modes needs further investigations. Although slip and twinning are both strain rate dependent, to our surprise, the bending of the annealed specimens presents a positive strain rate sensitivity. Hence, there must be an unknown mechanism behind the anomalous bending behavior observed reported here. Determining what mechanism accounts for the inverse strain rate sensitivity of the bending of the annealed AZ31 sheet deserves a thorough investigation.

\section{Summary}

We performed three-point tests on sheet specimens of a Mg AZ31 alloy at various strain rates. The as-rolled specimens presented a negative strain rate sensitivity in which the bending angle decreased as the strain rate increased. However, in the annealed specimens (annealing temperature $150{ }^{\circ} \mathrm{C}$ ), a positive strain rate sensitivity was observed, i.e., the bending angle increased as the strain rate increased. To the best of our knowledge, such abnormal bending behavior has not been previously reported for $\mathrm{Mg}$ alloys.

\section{Acknowledgements}

B. Li, S.J. Horstemeyer, A.L. Oppedal, Y. Hammi, P.T. Wang, M.F. Horstemeyer are grateful for the support from the Center for Advanced Vehicular Systems (CAVS) at Mississippi State University

\section{References}

[1] G.I. Taylor, J Inst Metals 62 (1938): 307-338.

[2] B.A. Bilby, A.G. Crocker, Proc Roy Soc. A, 288 (1965) 240255.

[3] J.W. Christian, S. Mahajan, Prog Mater Sci 39 (1995) 1-157.

[4] Q. Ma, B. Li, E.B. Marin, S.J. Horstemeyer, Scripta Mater 65 (2011) 823-826.

[5] J. Bohlen, M. R. Nurnberg, J. W. Senn, D. Letzig, S. R. Agnew, Acta Mater 55(2007) 2101-2112.

[6] B. Li, S.P. Joshi, O. Almagri, Q. Ma, K.T. Ramesh, T. Mukai, Acta Mater 60 (2012) 1818-1826.

[7] E. Taleff, L.G. Hector, Jr., R. Verma, P.E. Krajewski, J.-K. Chang, J. Materials Engineering and Performance 19 (2010) 488-494.

[8] L.G. Hector, Jr., P.E. Krajewski, E.M. Taleff, J.T. Carter, Key Engineering Materials 433 (2010) 197-210.

[9] R. Verma, L.G. Hector, Jr., P. Krajewski, E. Taleff, JOM 61 (2009) 29-37.

[10] T. Al-Samman, G. Gottstein, Mater. Sci. Eng. A 490 (2008) 411-420.

[11] M.M. Myshlyaev, H.J. McQueen, A. Mwembela, E. Konopleva, Mater. Sci. Eng. A 337 (2002) 121-133.

[12] A.G. Beer, M.R. Barnett, Metall. Mater. Trans A. 38A (2007) 1856-1867.

[13] Q. Ma, B. Li, A.L. Oppedal, W. Whittington, S.J Horstemeyer, E.B. Marin, P.T. Wang, M.F. Horstemeyer, Mater Sci Eng A, 2012, in press.

[14] S.L. Couling, J.F. Pashak, L. Sturkey, Trans of the ASM 51 (1959) 94-107.

[15] L. Zhang, G.S. Huang, H. Zhang, B. Song, Journal of Materials Processing Technology, 211 (2011) 644-649.
[16] J.C. Baird, B. Li, S. Yazdan Parast, S.J. Horstemeyer, L.G. Hector Jr., P.T. Wang, M.F. Horstemeyer, Scripta Mater 67 (2012) 471-474.

[17] M.R. Barnett, Z. Keshavarz, M.D. Nave, Metall Mater Trans A 36 A (2005) 1697-1704.

[18] M. Knezevic, A. Levinson, R. Harris, R. K. Mishra, R. D. Doherty, and S. R. Kalidindi, Acta Materialia, 58 (2010) 6230-6242.

[19] A. S. Khan, A. Pandey, T. Gnäupel-Herold, and R. K. Mishra, International Journal of Plasticity, 27 (2011) 688706.

[20] I.A. Maksoud, H. Ahmed, and J. Rödela, Materials Science and Engineering A, 504 (2009) 40-48.

[21] D.L. Yin, K.F. Zhang, G.F. Wang, and W.B. Han, Materials Science and Engineering A, 392 (2005) 320-325.

[22] J. Koike, T. Kobayashi, T. Mukai, H. Watanabe, M. Suzuki, K. Maruyama, and K. Higashi, Acta Materialia, 51 (2003) 2055-2065.

[23] M. R. Barnett, Materials Science and Engineering A, 464 (2007) 1-7.

[24] J. Koike, T. Kobayashi, T. Mukai, H. Watanabe, M. Suzuki, K. Maruyama, and K. Higashi, Acta Materialia, 51 (2003) 2055-2065.

[25] S. R. Agnew and O. Duygulu, International Journal of Plasticity, 21 (2005) 1161-1193

[26] J. A. Horton, C. A. Blue, T. Muth, A. L. Bowles, and S. R. Agnew, Magnesium Technology, Edited by Neale R. Neelameggham, Howard I. Kaplan, and Bob R. Powell, TMS 2005 .

[27] R. Hielscher, H. Schaeben, J Appl Crystallography 41 (2008) 1024.

[28] M.H. Yoo, Met Trans A 12A (1981) 409-418. 